\title{
A FAVOR NO ES EN CONTRA; EN CONTRA ES A FAVOR. POESÍA Y COMUNICACIÓN EN LA ACTUALIDAD
}

For is not against; against is for. Poetry and communication today

\author{
PABLO LÓPEZ-CARBALLO \\ DUKE UNIVERSITY IN MADRID (ESPAÑA) p194@duke.edu
}

RECIBIDO: 12 DE FEBRERO DE 2018

ACEPTADO: 28 DE MARZO DE 2018

\begin{abstract}
RESUMEN: El presente artículo aborda las implicaciones que ha tenido el modelo comunicacional como rasgo definitorio y exclusivo de la poesía española reciente. En estas páginas se traza una génesis de la construcción de categorías dicotómicas en el acercamiento al panorama literario en lengua española y los problemas asociados a esta forma de análisis. De igual modo, se pretende poner de manifiesto la complejidad de la comunicación poética y mostrar algunas prácticas discursivas que aprovechan sus posibilidades. Así, entendiendo la comunicación como una característica más de las que podemos encontrar en el poema, buscamos desde el análisis de cuatro poéticas actuales (María Salgado, Lucía Boscá, Su Xiaoxiao, Ruth Llana) presentar los diferentes cambios que se están produciendo en la creación y la crítica de poesía.
\end{abstract}

Palabras Clave: Poesía española, Comunicación, Lenguaje, María Salgado, Lucía Boscá, Su Xiaoxiao, Ruth Llana.

ABSTRACT: This article will tackle the implications that the communication model has had as a defining and exclusive feature of recent Spanish poetry. In these pages we will consider a genesis of the dichotomous categories' construction to analyze the literary panorama in Spanish language, as well as the resultant problems associated with this form of analysis. In addition, the article intends to highlight the complexity of the poetic communication and to show some discursive practices that take advantage of their possibilities. Thus, if we understand communication as another characteristic to be found in the poem, we will present the different changes that are taking place in the writing of poetry as well as its criticism in the present work of four poets (Maria Salgado, Lucia Boscá, Su Xiaoxiao and Ruth Llana) and their poetics.

KEYwORDS: Spanish poetry, Communication, Language, María Salgado, Lucía Boscá, Su Xiaoxiao, Ruth Llana.

López-Carballo, Pablo.

"A favor no es en contra; en contra es a favor. Poesía y comunicación en la actualidad".

Kamchatka. Revista de análisis cultural 11 (Julio 2018): 205-220

DOI: 10.7203/KAM.11.11496 ISSN: 2340-1869

Monográfico LECTURAS DEL DESIERTO: NUEVAS PROPUESTAS POÉTICAS EN ESPAÑA 


\section{INTRODUCCIÓN}

El afán clasificatorio del que adolece la mayoría de los estudios de poesía promueve cierto reduccionismo que, en lugar de abordar la complejidad que supone acercarse a cualquier panorama poético, subsume sus particularidades en categorías excesivamente abarcadoras y excluyentes. La tendencia está tan extendida y es tan común que la lógica del compendio, donde lo más habitual es que existan solo dos posturas a las que adscribir los textos, ha llegado a imponerse sobre cualquier intento de lectura crítica. Dentro de este esquema, en la poesía escrita en lengua castellana, nos encontramos con un claro binomio que condiciona su historia reciente. Se trata de la oposición entre un supuesto hermetismo y una supuesta claridad. Desde estas páginas trazaremos una génesis de la construcción de esas categorías, deteniéndonos en ejemplos paradigmáticos y remitiendo a los estudios que lo abordan en profundidad, para poder acercarnos a las implicaciones que conlleva la imposición de una de estas dos vertientes: el modelo comunicacional. De esta manera, después de explorar los problemas de considerar la comunicación como un rasgo excluyente, estaremos en posición de abordar diferentes poéticas que, mediante el análisis, nos mostrarán las diferentes posibilidades que alberga la comunicación en poesía, así como su complejidad. Es por ello que resaltaremos este conflicto, en las obras de María Salgado, Lucía Boscá, Su Xiaoxiao, Ruth Llana, y la necesidad de que la crítica no aplique categorías cerradas y previamente delimitadas sobre los textos.

Años antes de ser galardonado con el Premio Nobel, el poeta italiano Eugenio Montale respondía, desde las páginas de Primato en el verano de 1940, ante lo que en ese momento se estaba convirtiendo en la tónica dominante: ser considerado un poeta que rehuía la comunicabilidad del poema en favor de una supuesta y deliberada oscuridad. En esta dirección, saliendo al paso para desmentirlo y desmarcarse de cualquier atisbo de interpretación en la que el texto adquiriese el cometido de no comunicar nada, afirmaba:

No he buscado nunca a propósito la oscuridad y por ello no me siento muy cualificado para hablarles de un supuesto hermetismo italiano, si es que existe aquí, y yo lo dudo mucho, un grupo de escritores que tenga una sistemática no comunicación como objetivo (1995: 95).

Podemos partir de este claro ejemplo para comprobar cómo, a día de hoy, sigue siendo un lugar común (Cambon, 2014; Morabito, 2006) mencionar al poeta italiano, o a sus contemporáneos "los nuevos líricos", para ejemplificar el hermetismo literario — nada que ver con el filosófico - y cómo esta categoría se ha estandarizado en torno a una supuesta renuncia a que el poema tenga el objetivo de establecer una comunicación.

Otro de los autores apresados en estas dicotomías que pretenden sistematizar los panoramas es Nicanor Parra. Su caso, sin embargo, es contrario al de Montale. Durante mucho tiempo, la lectura de la poética parriana más extendida fue la realizada por Mario Benedetti, quien entendía que el autor chileno supeditaba a la comunicación todo el sentido frente a otros rasgos que podrían caracterizar al texto poético. El trabajo de Parra con la lengua coloquial y su interés en no cerrar posibles lecturas e interpretaciones han podido llevar a confusiones en cuanto a sus ideas en torno al lenguaje. Así, en las respuestas que ofrece en una entrevista al propio Benedetti, 
Parra expone la importancia de la comunicabilidad de sus poemas y la dimensión social de su poesía, otorgándole un papel central al hecho de compartir sentidos:

- ¿A ti de todos modos te importa la comunicación con el lector?

- Me parece indispensable. Me parece que el lector-interlocutor debe darse por aludido, porque ésta es una poesía que siempre está dirigida a un interlocutor, no a un interlocutor equis sino a un sector, a una parte de todo interlocutor posible [...] Los poemas no son monólogos, sino parlamentos de un diálogo.

- ¿Tú consideras la comunicación indispensable en tu poesía, por la calidad especial de ésta, o lo consideras indispensable para todo poeta?

- No tan solo para todo poeta. Me parece que la actividad central del ser humano debiera ser la comunicación [...] De manera que el interlocutor es para mí un elemento sagrado, que no tiene que ver sólo con el trabajo literario sino también con la presencia del hombre en este mundo (1972: 61-62).

En estas palabras del poeta chileno puede apreciarse tanto la importancia de la comunicación como el hecho de que no renuncia a ningún otro componente poético en favor de ella. Sin embargo, vemos cómo en la posición asumida por Benedetti en el prólogo sí que está presente esa jerarquización de los elementos constitutivos del poema. Esta postura se fundamenta, principalmente, en la creencia de que el poema debe asimilarse a las reglas de la comunicación cotidiana entre hablantes. Lejos de una postura tan simplificadora, el mismo Parra aclara su actitud refiriéndose a sus propios procedimientos poéticos:

Me pareció que el lenguaje habitual, el lenguaje conversacional, estaba más cargado de vida que el de los libros, que el lenguaje literario, y hubo un tiempo en que yo no aceptaba en los antipoemas sino expresiones coloquiales. Después me tranquilicé un poco y acepté también como elementos vitales las propias creaciones humanas. El lenguaje escrito es una creación del hombre, es una experiencia humana, y en cierta forma también es vida (1972: 51).

De esta manera, podría dar la impresión de que el procedimiento empleado por Parra se acerca a una consideración cercana a Benedetti. No obstante, una lectura atenta nos deja ver que el chileno no estaría hablando en el mismo plano de enunciación. En concreto, Parra lleva el lenguaje coloquial al poema pero no supedita su procedimiento estético a la comunicación con el lector. Por otra parte, el lenguaje coloquial — complejo y multiforme - al que hace referencia no tendría mucho en común con el empleo retórico y simplificador que promulga Benedetti. En Parra no hay interés por rebajar el discurso para hacerlo accesible de manera inmediata. De hecho, ese material va en direcciones contrarias y, en innumerables ocasiones, con unas intenciones que no encajan en la propuesta en la que Benedetti cree reconocer los mecanismos análogos que harían de Parra un poeta cuya finalidad es la de acercar el discurso al lector, sacrificando el tratamiento lingüístico. Por ello, cuando se refiere a su trabajo con el lenguaje, el poeta chileno matiza:

He tenido preocupaciones muy hondas con el uso de las palabras, pero una vez que se ha rescatado un lenguaje conversacional, de todos los días, resulta que esas palabras, en un segundo movimiento, están allí solamente para expresar realidades que están más allá de ellas mismas (1972: 52-53).

El problema que encuentra Parra en el lenguaje es complejo. No se trataría, simplemente, de un medio para alcanzar un fin, estético en este caso, sino que su nivel de significado excede lo 
evidente y requiere de una dedicación poética alejada del maniqueísmo. Además, debemos tener en cuenta que el poeta chileno no parte de una realidad dada, ni pretende divulgar un conocimiento prescrito y compartido por todos los hablantes, sino ofrecer al lector un texto en el que el poeta se ha involucrado para poner en cuestión el sistema de significación predominante. Refiriéndose a la inclusión de Nicanor Parra entre los poetas comunicantes, el crítico y poeta Eduardo Milán matiza la tendencia que parecía sostener a Benedetti como destacada punta de lanza en el acercamiento al lector:

El lector — esto se ve acentuadamente en el presente- no distingue entre un fino trabajo sobre la norma y una tosca copia de la oralidad a la que considera "natural"; entre la operación lingüística de Nicanor Parra, sostenido en un rigor teórico duro —el de "lo común verdadero" (Stanley Cavell)—, y un trabajo tosco, "de oído", sin ningún rigor propositivo formal, de muchos "poetas comunicantes" (2014: 208).

Esta distinción resulta fundamental para poder precisar la diferencia sustancial que desvincularía el trabajo poético de Nicanor Parra de los nominados como poetas comunicantes. No se trata aquí de que existan problemas vinculados a que una poética sea más o menos comunicativa. El problema estaría en asumir que la comunicación es la única posibilidad discursiva en el poema. De igual manera, aceptar la existencia de un término medio al referirse al lector, o establecer una dicotomía entre oscuridad y claridad, entre confusión y entendimiento, estaría reduciendo en exceso las posibilidades que alberga la práctica poética. El texto poético necesita estar en permanente construcción, no acepta la imposición de un carácter definitivo en el que se delimite, de una vez y para siempre, un virtual contenido transmisible porque no es un simple código de mediación. El adoptar este último punto de vista podría suponer la equiparación de cualquier experiencia vital y lingüística al entender la lengua como un sistema petrificado que sólo es capaz de transmitir aquello que resulta obvio o tiene un acceso inmediato. Pero lo más curioso es que esta postura también termina por afirmar que un poema comunica mucho menos de lo que realmente puede llegar a hacer si atendemos a la totalidad de sus elementos constituyentes, es decir, más allá de la función puramente comunicativa.

\section{EL DETERMINISMO DE LO PARADIGMÁTICO}

Lo que nos interesa resaltar con estos dos ejemplos paradigmáticos es la pervivencia en el tiempo y la extendida aceptación de un modelo como el descrito cuando nos referimos a la práctica poética. No es extraño seguir encontrando, más de medio siglo después, referencias a un supuesto hermetismo o a la necesidad de comunicabilidad absoluta del poema para llegar al lector, pese a que, como ha quedado demostrado en numerosas ocasiones, esta postura reduce lo literario al paroxismo más simple. Resulta posible rastrear, todavía en nuestro contexto, cómo algunas manifestaciones intentan hacer pervivir estas dicotomías, sin duda cuestionables desde un punto de vista crítico. Tal es el caso de Poetas ante la incertidumbre (2011), que gozó de una gran repercusión mediática y rescataba estos preceptos intentando, más que proponer algo, excluir todas aquellas prácticas que no asumieran su centralidad dentro del espectro poético. En este volumen colectivo, sus integrantes firman un manifiesto titulado Defensa de la poesía, en el que dejan fuera de lo poético cualquier aportación que no cuente con la posibilidad de ser entendida por el lector "normal". Al margen de cuestiones en las que no podemos entrar ahora, como la 
delimitación de este último término o la infructuosa necesidad de decir lo que sí y lo que no es poesía, otra interesante cuestión es que se establece de nuevo aquí una dicotomía que reduce el panorama literario a dos posturas enfrentadas y, de acuerdo con la argumentación recogida, irreconciliables. En este caso se retoman los postulados de un tipo de crítica (García Martín, 1988; Jiménez Millán, 1994; García Montero, 1996) que entiende como un bloque homogéneo, compacto e igualitario toda práctica ajena a la defendida por los propios críticos. Esta reducción y asimilación es la que ha asumido una parte la crítica posterior, que encuentra satisfactorio poder hablar con categorías abarcadoras y sin la necesidad de aportar una argumentación que respalde estos juicios uniformadores.

No son pocas las ocasiones en las que se han analizado estas dicotomías mostrando su inutilidad o escaso acierto a la hora de aglutinar las poéticas representadas (Casado, 2006; Schop, 2000). Así, una de las problemáticas más extendidas en España, la conocida como "conocimiento versus comunicación”, continúa originando una extensa bibliografía (Benéitez Andrés, 2018; López Carballo, 2017; Lanz, 2007; Mora, 2006) motivada por la relevancia que este enfrentamiento ha mantenido dentro del panorama nacional, tanto en los años cincuenta como sesenta y décadas posteriores. Esta perdurabilidad en el tiempo tiene su razón de ser en las implicaciones en torno al lenguaje poético que se pusieron en marcha en la discusión inicial. En nuestro caso, además de esto, deberíamos resaltar las diferentes posturas en torno a la conexión con el lector que se abordaron desde la primera confrontación con las tesis de Castellet en La hora del lector (1957). Pese a un uso terminológico bastante indeterminado, muchas de las posturas defendidas ya a mediados del siglo XX coincidían en que la poesía es "una manera específica de tratar el lenguaje, y que la dignidad de ese lenguaje no debía menoscabarse en ningún momento en aras de una determinante preceptiva temática" (Rubio y Falcó, 1981: 73). En el mismo sentido se muestran los planteamientos de José Ángel Valente en torno a la creación y el papel del crítico frente al poema. Oponiéndose al entramado teórico defendido por Bousoño (1952), destaca la necesidad de pensar en el poeta como creador y no como transmisor de una experiencia previamente delimitada:

El acto creador aparece así como el conocimiento a través del poema de un material de experiencia que como compleja síntesis y en su particular unicidad no puede ser conocido de otra manera [...] Hay una cara de la experiencia, como elemento dado, que no puede ser conocida más que poéticamente. Este conocimiento se produce a través del poema (o de las estructuras equivalentes en otros aspectos de la creación artística) y reside en él. Por eso el tiro del crítico yerra cuando en vez de dirigirse al poema se dirige a la supuesta experiencia que lo ha motivado, buscando en ésta la explicación de aquél, porque tal experiencia, en cuanto capaz de ser conocida, no existe más que en el poema y no fuera de él. (1963: 159).

Estas palabras de Valente podrían servir para dirigir la controversia hacia otros territorios más fecundos y empezar a hablar de comunicación en un sentido más complejo que el que deriva de la equiparación del lenguaje en el poema con el uso social que tiene lugar fuera de él. Lejos de representar un punto de inflexión, las palabras de Valente han seguido siendo necesarias como contrapeso teórico ante los insistentes intereses por reducir el discurso poético a un acto en el que el lenguaje es solo un código. El grupo Alicia Bajo Cero (1996) se ocupó de analizar algunas de las prácticas que defendían estos planteamientos para descubrir un discurso ideológico que 
promulgaba una concepción del hecho poético en la que el lenguaje seguía siendo considerado como vehículo transmisor de los sentimientos, que pasaban intactos desde el poeta hasta el lector. De igual modo, años después, un integrante de este colectivo, Antonio Méndez Rubio, retomaba algunos de esos planteamientos y reflexionaba sobre las implicaciones de ese tipo de constructos y sobre cómo este impulso convertía las obras literarias en meros objetos de consumo, fácilmente trasmisibles, y en donde forma y contenido no necesariamente guardaban una relación. Además de escribir una historia de la literatura nacional sesgada y plana:

En coherencia con este planteamiento propagandístico, fue meticulosamente borrada del mapa cualquier alteridad como si, por el mero hecho de serlo, fuera ya per se una alteridad no válida, impertinente, estéril. Por ejemplo, el término tradición, en singular, se usó a menudo como arma arrojadiza contra toda posible diferencia o disidencia. Tradiciones estéticas modernas como el romanticismo o la vanguardia fueron una y otra vez expulsadas de la república (2004:124).

Se buscaba ofrecer con ellos una única lectura de la poesía predecesora, intentando que todo aquello que no encajara dentro del molde preestablecido no entrase a formar parte de la ecuación poética. Estas maniobras afectaban de manera decisiva a las relaciones que se podían establecer entre el lenguaje y el mundo, y simplificaba estos términos hasta el punto en el que no existía tensión entre ambos. En este sentido, las poéticas que pretendían explorar el conflicto existente entre esos términos eran repudiadas y desposeídas de cualquier rasgo diferenciador. Así, se las incluía a todas en el mimo saco y se les atribuían características que, en muchos de los casos, ni siquiera eran rastreables en los textos. Específicamente, una de las cuestiones que más llama la atención de esta manera de proceder es la de calificar a esas poéticas disímiles como no comunicativas, presuponiéndoles un abandono de las posibilidades sociales que alberga el poema. De esta manera, se conforman dos posturas enfrentadas, omitiendo cualquier punto intermedio entre ambas, como si fueran un binomio irresoluble. Pero el problema de fondo no es tanto la centralidad de un rasgo, sino la declarada inutilidad de todos los demás, como si un poema solo y exclusivamente pudiera ser comunicativo. Las implicaciones que tiene esta concepción de lo poético las sintetiza muy bien Lenore Gale, en su estudio dedicado a la comunicación en la poesía hispanoamericana, a propósito de las posibilidades que alberga el lenguaje:

En cierto sentido, la fe en la palabra comunicativa conlleva una suerte de desconfianza, y hasta de escepticismo, con respecto a las potencialidades [...] de los vocablos. Pues, en la medida en que considera que éstos son meros instrumentos de información que remiten a una realidad externa, el poeta estaría disminuyendo la posibilidad de crear una nueva y más amplia gama de connotaciones dentro del texto mismo. En el plano del lenguaje, se encerraría, irónicamente, dentro de una realidad a la que, más bien, está queriendo atacar (1981: 240-241).

De esta manera, en lugar de enriquecer el texto y el diálogo sobre el afuera, se crearía una realidad paralela en la que los textos encontrarían su razón de ser de acuerdo a unos estándares ajenos a ellos mismos. Así, se transmite una realidad delimitada previamente, produciendo una confusión entre el significante y el significado. Al otorgarle más relevancia a este último frente al primero, "el poeta tiende a comportarse como si el empleo de un habla fragmentada, de ritmos torpes, de giros coloquiales o vulgares, señalara automáticamente una ideología que mirase con simpatía a los oprimidos" (1981: 241), dando por hecho que cualquier otra opción estética estaría 
marcada por un procedimiento reaccionario, elitista, o, peor aún, carente de fundamento. Vicente Luis Mora ha señalado con acierto las limitaciones que suponen este tipo de proyectos cimentados sobre bases comunicativas. Según Mora, podríamos encontrar en este tipo de propuestas los siguientes puntos:

1. Que hay una realidad exterior (y, por tanto, opuesta o diferente a la interior). 2. Que esa realidad puede ser conocida por un observador cualquiera. 3. Que por tanto, ese observador puede comunicarla mediante el poema. 4. Que el lector va a entenderla de la misma manera que ha sido expresada y, por tanto, el conjunto fenoménico de 1 va a permanecer inalterado e idéntico a sí mismo en 4 (2006: 64).

Curiosamente, esta paradoja ha sido asumida con naturalidad y ha llegado a nuestros días. Una muestra la encontramos en el recurrente binomio que suele emplearse para reducir, bajo la etiqueta de no figurativa o abstracta, a toda postura ajena a ese planteamiento. Su pervivencia se explica por la simpleza de sus términos y por la posibilidad de que el lector relacione la categoría con cualquier práctica, permitiendo así una ilusión de entendimiento. El principal problema que tiene asumir este esquema es que la crítica no necesita de las prácticas y, en lugar de partir de los poemas, optan por reproducir un panorama carente de profundidad. Por ejemplo, en una entrevista reciente, José Luis Morante, autor de una antología sobre poesía actual que gozó de gran repercusión, Re-Generación (2016), se refiere en estos términos a una posible genealogía de la poesía española reciente:

Los dos caminos habituales del legado poético en castellano han sido - mis disculpas por el esquema simplista-, el realismo figurativo y la abstracción. En la distancia que separa ambos trazados se han ido gestando atajos y bifurcaciones que acercan la semántica de las dos etiquetas. El presente poético guarda fidelidad a este legado y en él conspiran dos actitudes de taller: el conformismo sedentario y el nomadeo de la experimentación; de todo ese magma se compone el sustrato poético del siglo XXI (Morante, 2016).

Pese a las disculpas, en la antología se aprecia claramente esta tendencia a las etiquetas ya consensuadas, en donde los textos ofrecerían matices que añadir al discurso pero sin invalidar, en ningún caso, este planteamiento dicotómico. Además, estos discursos incorporan otra etiqueta prefabricada como es la de la pluralidad, que parece justificar la pervivencia de las categorías. El procedimiento es simple: se eligen representantes de unas poéticas que no existen y, curiosamente, se hace hincapié en que las "disputas" ya están superadas. Pero el ejemplo más llamativo de esta tendencia, y acaso inaugural de esta etiqueta de sincretismo, es el de la inclusión de Jorge Riechmann en la antología Postnovísimos o, más recientemente, en La inteligencia y el hacha de Luis Antonio de Villena (2010), apelando a una poco documentada y superficial idea de pluralidad.

Este recorrido ha querido evidenciar cómo la comunicación ocupa un lugar destacado en una parte importante de las discusiones y concepciones poéticas contemporáneas y que, en muchas ocasiones, se emplea como rasgo decisivo y definitorio del hecho poético. Igualmente, el componente comunicativo del poema se ha utilizado como coartada partidista para dejar poéticas al margen o para marcar diferencias entre modelos poéticos. Pero lo que más llama la atención en nuestra tradición reciente es la insistencia en asumir la comunicación con una única perspectiva, con ánimo de seguir fomentando unos binomios en pugna. De este modo se explica la 
consideración o calificativo de no comunicativas, o herméticas o cualquier otro eufemismo, para referirse a todas aquellas poéticas que se muestren disconformes con la asunción plena de una determinada perspectiva de la comunicación en poesía.

\section{UN ESCENARIO OTRO}

Por todo ello se hace necesario replantearnos los diversos escenarios que alberga la poesía española actual, que no pasan por contraponer dos formas de creación estandarizadas sino que, muy al contrario, gozan de una gran singularidad y, al tiempo, variedad. Un contexto que nos enseña que la comunicación puede ser un elemento muy destacado en poéticas que habitualmente son tachadas de herméticas o complejas. Por eso, buscamos poner de manifiesto ahora cómo este elemento presente en el poema puede ser entendido desde una diversidad de perspectivas que enriquecen el discurso literario. Las poéticas de María Salgado (Madrid, 1984), Lucía Boscá (Valencia, 1985), Su Xiaoxiao (Madrid, 1989) y Ruth Llana (1990) nos sirven de ejemplo a la hora de complejizar la relación texto-mundo en la búsqueda de significado. Cada poética, desde una posición muy diferente, da cuenta de una relación individual con el lenguaje, que al tiempo se inserta en una colectividad social y que trata de responder a los problemas y posibilidades que esta doble pertenencia — la de la poeta pero también la del lenguaje- genera. En todas ellas hay un claro interés por comunicar, por establecer nexos más allá del poema, pero sin supeditar el resto de elementos constituyentes a este objetivo. Por eso, más bien habría que hablar de adaptación continua a los conflictos que van encontrando en la escritura y de un deseo por ampliar las posibilidades significativas.

En los poemas de Ruth Llana se aprecia, a simple vista, una estructuración que rehúye el concepto tradicional de poema. No podemos acercarnos a sus textos con la misma mirada que lo haríamos a una composición clásica, desde luego, pero no por ello se nos exige descartar las posibilidades comunicativas que encontramos. De hecho, en sus tres libros publicados hasta la fecha, tiembla (Point de Lunettes, 2014), estructuras (Ejemplar único, 2015) y umbral (Malasangre, 2017) una de las características comunes es, precisamente, el continuo intento por establecer nexos con el afuera del poema. La poeta parte de una clara conciencia lingüística, atendiendo a las múltiples caras de la composición textual — desde lo puramente técnico hasta una relación personal con la lengua - y el devenir que acarrea en las diferentes formas que adoptan los textos. Sin ir más lejos, en su primera publicación, tiembla, este sistema de composición hace que, por ejemplo, las palabras parezcan atraerse unas a otras generando un tejido lingüístico complejo en el poema, así como una forma particular en cada ocasión. Algunos recursos empleados por la poeta podrían llegar a confundir en una primera lectura, pero al analizar el funcionamiento interno de los textos, las inversiones y torsiones de la tradición salen a flote. Una muestra de ello es el empleo de la repetición, que habitualmente se utiliza para reafirmar o enfatizar, y que aquí funciona para desviar significados. No se trata de un juego disuasorio, al contrario, la poeta busca la precisión, el matiz, intenta transmitir algo que con la simple producción ordenada de palabras no lograría comunicar en ningún contexto. En otras ocasiones, los poemas se llenan de acciones yuxtapuestas con un resultado similar al descrito. 
En este primer libro hay dos planteamientos decisivos: el binomio formado por la superficie y la profundidad, y la importancia que adquiere la direccionalidad. El primero se refleja de forma clara a través del continuo juego de contornos, de límites, incluso podríamos hablar de una aproximación a la idea de romper con las barreras o fronteras que habitualmente delimitan lo que existe y lo que no. Hay cierta desconfianza hacia ello, algo que también se hace notar en sus otros libros. El planteamiento adoptado es el de ver lo que ocurre cuando esas ideas chocan, cuando de pronto algo que estaba en una parte, en el poema, pasa al otro lado. Con esa maniobra se rompe, desde luego, la jerarquía y la categorización de la lengua cotidiana; los elementos del poema se reestructuran en función de otros parámetros nuevos. Un indicio de esto último es cómo el cuerpo se introduce en la dinámica del sueño y cómo éste se revela extraño, contrastando la efervescencia con su peso, su forma y su imposibilidad de modificarse fácilmente. Precisamente, este continuo juego de límites es el que se potencia en umbral de manera mucho más orgánica y desenvuelta. En cuanto a la segunda característica apuntada, la importancia de la direccionalidad, se nos muestra ésta en la especial relevancia que cobran los proyectiles y las trayectorias. Encontramos, cuantitativamente hablando, continuas referencias a "balas" (pp. 33 y 36), “cañones" (pp. 29, 33, 34, 40 46), “disparo" o "disparar" (pp. 22, 24, 29, 30, 33 у 44), "tiros" (pp. 34-37) e, implícitamente, la acción del arquero. En todos estos textos, las direcciones que toman esos proyectiles, las esferas que conectan, o las posibilidades semánticas que abren son decisivas para la construcción del poema. Hay también un juego entre la vida y la muerte, que podríamos entender nuevamente como límite o como membrana que termina de poner en contacto dos partes en un mismo plano de realidad. Leemos en umbral: «todo sucedió con la velocidad de un disparo» (p. 27); un poema donde una piedra es lanzada sin llegar a caer nunca, o al menos dentro del texto, que no hace sino resaltar la importancia del fragmento y los trayectos.

Si retomamos el análisis compositivo de los poemas, surge la posibilidad de establecer paralelismos entre los diversos libros. Hay una constante, que en algunos textos se aprecia más que en otros, desde luego, pero que no deja de ser recurrente, y es que las acciones se acumulan en los textos y no coinciden en el mismo eje de coordenadas temporales, sino que se yuxtaponen. En ocasiones se trata más de una sucesión de emociones que desean más una forma que un pensamiento claro y delimitado, o de un relato secuenciado. De ahí también que cobren especial relevancia los sentidos como el tacto o el oído en sus libros. En tiembla encontramos poemas en los que son del todo centrales (11-14); en umbral se entretejen con otros sentidos, habitualmente más asociados a la creación, como la vista. También en esta misma línea en torno a las emociones es donde habría que hacer significar la relación filial que se traba en muchos momentos: no se trata de una relación evidente y reconfortante, sino que aparece entre la inocencia y lo monstruoso, entre la pérdida y lo inasumible, lo visible y lo oculto, lo que se puede y lo que no se puede mostrar. La construcción de esta dialéctica constructivo/destructivo la encontramos también en torno a la memoria, como una necesidad y como aniquilamiento. En definitiva, en los poemas de Ruth Llana la forma es el resultado de la relación que la poeta establece con el lenguaje y de la necesidad y el deseo de transmisión.

La comunicación en los poemas de Su Xiaoxiao funciona de manera diferente y las elecciones compositivas, como no podría ser de otro modo, se resuelven en otras posibilidades. A grandes rasgos, parece haber un interés por generar un espacio textual que haga posible problematizar el sujeto. Hay una dicotomía dentro/fuera que funciona en este plano textual, igual 
que lo hace entre los límites del cuerpo. En el primer caso, es evidente el interés por elaborar un entramado textual en el que configurar un mundo referencial en sí mismo, que no trabajaría nombrando el mundo desde fuera del poema. Tampoco el lenguaje se erigiría como transmisor fidedigno de un contenido. Las relaciones que se establecen en los poemas van más allá de ese vínculo y ofrecen la posibilidad de comunicar mucho más contenido y conflicto que el resultante de un plano de enunciación convencional. De esta manera, se pretende transmitir una experiencia en la que lo sensorio-corporal adquiere una gran importancia, sin la necesidad de que esto se haga evidente de un modo descriptivo. Lo que se establece en el poema es un territorio de lenguaje. Las cosas del mundo entran al poema y comienzan a actuar de un modo desconocido, el lenguaje se vuelve así el único territorio del poema.

Desde el título de su primer libro, La casa de la ciénaga (Ártese quien pueda, 2015) ya nos pone tras la pista de la construcción de un espacio particular y definido. Se pretende fijar así un lugar estable, representado por la casa, una estructura para habitar en ella. Pero ya en el mismo título aparece con rotundidad la ubicación espacial de esa construcción, sobre el cieno, sobre un terreno para nada estable y que condiciona la vida. La primera sección, «el pozo de las horas», es una demarcación nocturna, que comienza desdibujando el límite de la propia noche con un poema breve titulado "madrugada", en el que el sujeto poético afirma que "nadie sabe de la madrugada" (11). Se ofrece así la posibilidad de perfilar un espacio al que accedemos a oscuras y en el que vamos a encontrar cierta resistencia si intentamos salir de él, porque, siguiendo la lógica interna del texto, tampoco nadie sabe "ni de su áspera corteza" (11), continúa el mismo poema. Este es el marco en el que los primeros poemas se desenvuelven, ejerciendo un poderoso contexto para el resto del libro. Los marcadores temporales, pese a su clara vocación de ofrecer unos asideros firmes, suponen una continua puesta en jaque del equilibrio, ya que van acompañados en todo momento de una inquietud que parece asociar una percepción de la medida del tiempo diferente a la que proclaman. En este juego de percepciones en torno al lenguaje, algunas palabras parecen tener más peso que otras y se aíslan en los versos. De ahí también deriva el ritmo cercano a la respiración, entrecortado, que provoca una estructura similar. Esta percepción aparece matizada por condicionantes que atañen al cuerpo: ceguera, sordera, o cojera, entre los más llamativos. De esta forma volvemos a encontrar otro elemento que nos hace pensar en el correlato de la casa como cuerpo, igual que la casa podría serlo también de la poesía.

En la siguiente sección, «el límite», resulta evidente desde la cita de Birgitta Trotzig que la referencia del título alude al cuerpo, a ese límite físico que nos separa del exterior. En el poema "rostro" se desdibuja el cuerpo de la mujer y en "dentro" el sujeto poético especula con diferentes contenedores, con ubicaciones que no hacen sino hacernos pensar en la violencia padecida y en la memoria de ese dolor. Esto mismo se hace evidente en la sección «las pasiones del cuerpo», donde se muestran decididamente la enfermedad, el dolor y las partes del cuerpo desde un punto de vista que busca ponerlo en conflicto. La idea de límite sigue teniendo vigencia en todo el libro, siempre asociada a la violencia y a la enfermedad y, por ejemplo, en la sección «en torno al amor y al odio» la violencia recibida se transforma hacia el exterior, desdibujando en cierto modo la diferenciación entre el afuera y el interior. Se resuelve así difusamente una posible identidad que no deja de estar condicionada por el entorno social y por las categorías preestablecidas que coartan y subordinan ese límite físico. En esta dirección leemos un poema en el que el sujeto poético se pregunta por quién es ante el espejo, "solo tengo piel en las manos de 
los otros" (39). Ese efecto de falta de autonomía también podría ser interpretado como sometimiento desde el exterior, con lo que nuevamente la frontera divisoria se desdibuja. Ese impulso encuentra relación, como ya apuntábamos anteriormente, en la relación de la casa con las concepciones poéticas. De este modo, vemos que en algunos textos el exterior parece inundar la página y el poema surge por sustracción; el sujeto poético trata de poner orden, de conducir las palabras a través del relato. Según avanza el libro, ese hilo se concreta en la sección «las pasiones del cuerpo» o en el poema "en torno al amor y al odio", aunque más decididamente en «la casa de la ciénaga» y «desembocadura»; aquí la narración gana espacio. Sigue teniendo importancia el extrañamiento del cuerpo, la percepción fragmentada de las cosas del mundo, como desgajadas de un todo, y la intemperie, mientras se va abriendo paso la necesidad de contar, de construir relato. Parece haber un convencimiento de que los hechos son importantes para poder dar cuenta de las percepciones y de los conflictos.

En cuanto al interés por contar y por construir relatos, la obra de María Salgado resulta paradigmática, aunque su exposición se organiza desde concepciones muy diferentes a las planteadas por Su Xiaoxiao.

En la poesía de María Salgado se percibe un claro interés por pensar el lenguaje al margen de lo establecido, buscando la posibilidad de reorganizar el mundo, o dar cuenta de un pedazo de él, desde el texto. De ahí que esta investigación le lleve a ensanchar los límites del poema, convirtiendo su poética en una experiencia de lenguaje que toma como punto de partida la carencia de formas preestablecidas, o correctas, para el poema. En consecuencia con este planteamiento, asume la complejidad del mundo, repleto de signos, significados y sentidos para rescatar desde esa especie de "lleno" lo que terminará conformando el poema. En este caso, la manera que tienen las palabras de llegar al poema describiría una trayectoria clara desde fuera hacia el texto. No se trataría de una simple traslación, ni de asumir la coherencia o la jerarquía de esas palabras en el contexto en el que surgen, sino de aprovechar lo que en ellas se muestra de revelador y de explotar su complejidad, y la complejidad del mundo, desde el conflicto de la escritura. El objetivo es entresacar sentidos y conflictos del murmullo social. En esta acción hay un claro posicionamiento ético, que busca subrayar la dimensión política y el papel social de la poesía. Por una parte, existe cierto interés por visibilizar realidades que habitualmente están silenciadas, intentando en todo momento dar cuenta de aquello que no es visible a simple vista o que los diferentes lenguajes ocultan deliberada o arbitrariamente, haciéndolo pasar por "normal". Por eso, María Salgado escapa de los lenguajes estandarizados, pautados o petrificados, para poner el acento en la lengua en construcción, especialmente el habla, que sería el paradigma de código en continua mutación y cambio, así como el elemento básico de cualquier lengua basada en la oralidad. Estas formas, en contraposición al uso escrito y a la lengua considerada como literaria, son tratadas como residuos. Hay un interés en la obra de Salgado por construir sus poemas con esas formas descartadas, esos residuos aparentemente inservibles en los que, en realidad, se esconde el conflicto social y también estético.

Por eso, para esta poética resulta esencial la actitud de escucha. En la poesía de María Salgado esta posición es tan determinante como el mirar o el pensar. La acción de poner el oído, la de sentarse a escuchar o, al otro lado, la de un receptor que se deja llevar resultan fundamentales para esta concepción de la poesía. Buen ejemplo de ello es el trabajo Hacía un 
ruido. Frases para un film politico (Contrabando, 2016), publicado recientemente en forma de libro, en el que la poeta recopila frases oídas en torno al 15 de Mayo del año 2011, que pasan a ser trabajadas en relación a otros materiales construidos por la autora. En ese cruce de materiales, algunos parecen partir de esas palabras extraídas de contexto, otros asemejan querer dar cuenta de esos contextos para mostrarlos en efervescencia y unos terceros querrían problematizar cuestionando el papel del poeta o el posicionamiento frente al lenguaje- la propia tarea poética emprendida por Salgado. Esta tarea de extracción también puede interpretarse como una maniobra que busca rescatar las formas del olvido, intentando que esas palabras, o combinaciones de palabras, no se mueran en la debilidad del lenguaje oral, sino que, de algún modo, permanezcan, no por un ansia de perpetuarse como modelo sino más bien para todo lo contrario: escenificar la dependencia entre habla y situación comunicativa. Y es que aquí también está implícita la idea de que, a veces, el mundo se construye desde la precariedad, y no hay otra posibilidad que mostrar esas frases deshilachadas, esas palabras débiles o esas yuxtaposiciones ingenuas, para dar cuenta de las cosas que en él ocurren.

Los dos movimientos descritos, tanto la escucha como la sustracción al caudal comunicativo general, además de generar un espacio en el poema, pretenden generar un espacio de comunidad. No en balde Hacía un ruido también se ha ofrecido en forma de un recital en el que la poeta se abría hacia otras artes, especialmente el trabajo de experimentación sonora con Fran MM Cabeza de Vaca: no hay duda de que también las artes escénicas tienen un papel destacado, pues esa apertura, finalmente, se dirige hacia el público. Los textos de María Salgado buscan un interlocutor que construya la pieza en cada momento. Sin esas presencias la obra no tendría sentido, igual que tampoco lo tienen las palabras sin las personas que las pronuncian. Si uno de los lemas más destacados del 11M era "tomar la plaza", esa conquista espacial y ese interés por recuperar los lugares para lo común pueden trasladarse perfectamente a la obra de Salgado, como si de "tomar la poesía" se tratase. Es en ese espacio conquistado en el que la poeta busca el diálogo. Un espacio físico ganado para la poesía, en donde no solo está presente la palabra, también el cuerpo con toda su potencialidad puesta en juego. No se trata de decir que la poesía no es lenguaje, o que también puede ser otra cosa; no, para Salgado la poesía es lenguaje pero consigue añadirle una mayor presencia, algo físico. En definitiva, cimenta con la palabra un espacio desde el que hacer surgir el diálogo, la comunidad y la posibilidad de construir.

Los poemas de Lucía Boscá no se asemejan a los de Salgado, aunque parten de una necesidad común, que es la de rescatar de ese magma ingente de lenguaje las palabras que acabarán constituyendo el poema. La comunicación en Boscá no busca tanto construir un espacio de comunidad como encontrar un interlocutor desde el texto. En su primer libro, Ruidos (2014), se aprecia un continuo cuestionamiento de las posibilidades del lenguaje sin que éste quede reducido a lo obvio, haciendo que este cuestionamiento surja en la escritura, que se da como algo indispensable y necesario en la tarea de la poeta.

El libro se estructura en cinco partes. En la primera de ellas, «Escuchar», se aprecia un punto de partida apegado a la acción que le otorga el título. La escucha es entendida aquí como un argumento amplio en el que se destaca la actitud de espera, de observación y de percepción desde la calma, tanto del mundo como del poema. Es un proceso de aprendizaje en el que el tachado revela las dudas existentes en esta fase. No parece casual que sean las preguntas lo que de 
forma más predominante aparezca tachado. Además, su naturaleza titubeante parece indicarnos el cariz que se añade a la dirección de las preguntas: ¿se construyen hacia fuera del poema? ¿van hacia el poema? La respuesta a estas cuestiones no sería lo importante aquí, sino que lo revelador estaría en la huella que dejan y en la propia acción. Lo que nos interesa resaltar ahora es el interés por comunicar, el deseo por conectar y establecer una comunicación, un vínculo entre el texto y el exterior. En la segunda parte del libro, «Sacrificar», las preguntas ya no aparecen tachadas y surgen con mayor decisión. La actitud de aprendizaje se ve ahora turbada por la predominancia de la pérdida, lo que supone un cambio en relación a la primera sección. Podemos intuir cómo la inocencia, habitualmente asociada a la infancia aunque gestionada en cualquier proceso y experiencia vital, se resquebraja. En este apartado el vínculo con el mundo infantil resulta evidente, mientras que en los siguientes esa inocencia se va perdiendo, además, en favor de la culpa o la enfermedad. Por eso ahora el relato que se genera en torno al cuerpo ya no es tanto de pérdida como de padecimiento. En este contexto, el lenguaje violenta al cuerpo y las formas del poema se ven cada vez más alteradas, generando una semántica compleja.

Todos los poemas muestran una resistencia a la fijación de significados que provoca el paso el tiempo. La poeta busca, por ello, un nuevo tiempo para el poema, e intenta romper con esos significados para poder construir algo que le permita transmitir una idea, una acción, un sentimiento más allá de lo evidente. En la tercera sección de Ruidos, «Representar», este impulso para enfrentar la petrificación se manifiesta con mayor fuerza. Pero, en este caso, la poeta se encuentra con la fragilidad de la representación y la precariedad de la tarea. Así, tanto en esta sección como en las siguientes las cosas del mundo comienzan a entrar en el poema y los textos surgen de la tensión que se genera al trabajar con el material verbal. Se produce así la experiencia de lenguaje, en la que la poeta moldea y trabaja con la forma. Aquí radica una de las cuestiones capitales de su poética, rastreable también en los poemas que Lucía Boscá ha publicado en diferentes revistas con posterioridad a la aparición del libro del que venimos hablando, y que consiste en no caer en el engaño de la forma. Por una parte está la asunción de la particularidad del poema, en donde esa apariencia de las formas del mundo puede llevar al equívoco de querer ser concebida de un modo análogo, cuando la mediación que supone la apertura del espacio poemático impide ese tipo de traslaciones transparentes y directas. Los problemas que genera el lenguaje en el poema requieren de una solución técnica que no se puede sortear. Por ello, en Boscá hay una continua reflexión en torno a la poesía, como ya comentábamos anteriormente al hilo de las posibilidades del lenguaje. Por otro lado, detrás de las formas siempre suelen encontrarse usurpaciones o desvíos que terminan por neutralizar el lenguaje o convertirlo en un catálogo de usos instrumentales. Por eso en esta poética se trasluce la necesidad de tomar partido, de comprometerse con el lenguaje para no decir lo que otros quieren que digas, para no ser anulados y resultar cómodos y asumibles desde posiciones hegemónicas y aparentemente desinteresadas.

La toma de posición frente al lenguaje resulta determinante y supone un compromiso que va más allá de lo puramente textual o, precisamente, porque la única posibilidad de ir más allá de lo puramente textual es asumir ese compromiso. Así, la poesía no intentaría cerrar sentidos o interpretaciones, sino abrirlas, generar más sentidos que posibiliten el diálogo y el lugar de encuentro con el lector en el conflicto y no en el lugar común. Los poemas de Lucía Boscá no pretenden conformar unidades cerradas, se percibe en todo momento lo fragmentario de los 
procesos. Se trata más de una actitud frente al texto que de una composición de un todo consumado.

\section{APERTURA DE POSIBILIDADES A MODO DE CONCLUSIÓN}

Las cuatro poéticas analizadas aquí son un claro ejemplo de que la importancia de la comunicabilidad en el poema, o el establecimiento de conexiones entre el poema y el mundo, nada tiene que ver con la trasparencia de los textos. Desde la génesis trazada, se ha tratado de mostrar cómo la estandarización de posturas en el acercamiento a los poemas no favorece a la hora de dar cuenta de la complejidad de las poéticas, ni tampoco beneficia la profundización en rasgos de capital importancia como la comunicación. De las diferentes referencias ofrecidas se desprende la necesidad de no continuar con un tipo de lectura dicotómica, así como no simplificar los componentes textuales y su alcance.

Parece evidente que no es necesario otorgar a la comunicación el papel determinante — por encima de todo el resto de elementos constitutivos del poema- sino que, justamente, cuando ese diálogo se potencia éste termina por favorecer y fortalecer el resto de conflictos puestos en juego en los textos. Las relaciones que se establecen en el poema, así como las que se puedan generar con el afuera, poseen una naturaleza inabarcable y en continuo cambio que, afortunadamente, permiten la existencia de diferentes ideas y concepciones sobre el hecho poético.

Algo tan manifiesto como que las palabras del poema no son simplemente instrumentos informativos sobre una realidad exterior y bien delimitada puede resultar un gran obstáculo para aquellos críticos que prefieran generar un espacio de supuesto consenso. En esa delimitación de las posibilidades de los poemas y de la petrificación del lenguaje, que deja de ser algo en construcción y cambiante para ser algo invariable, es donde se simplifica la creación. En este orden basado en la reducción comienzan a quedarse fuera del panorama muchas posturas poéticas, y otras pasan a ser leídas sin atender al conflicto que las motiva. Es así cómo se cercenan las posibilidades de conexión entre poesía y realidad y, paradójicamente, pese a que se supone todo lo contrario, se reduce la riqueza comunicativa de los textos. En definitiva, lo que se ha tratado poner de manifiesto a través de estas cuatro poéticas es que la comunicación alberga muchas posibilidades, que no deben ser limitadas por una interpretación interesada del propio concepto de comunicabilidad. Es así como podemos plantear que la comunicación apela a la apertura de espacios para el intercambio y no a la simple transmisión de paquetes de sentido. 


\section{BIBLIOGRAFÍA}

BenedeTtT, Mario (1972). Los poetas comunicantes. Montevideo: Biblioteca de Marcha.

BenÉITEZ Andrés, Rosa. "Poesía como conocimiento frente a poesía como comunicación: una querella de largo recorrido". Rilce. Revista de Filología Hispánica 34 (2018).

BoscÁ, Lucía (2014). Ruidos. San Sebastián de los Reyes: Universidad Popular de San Sebastián de los Reyes.

BosCÁ, Lucía (2017). “Poemas”. Uno y cero ediciones.

Bousoño, Carlos (1952). Teoría de la expresión poética. Hacia una explicación del fenómeno lírico a través de textos españoles. Madrid: Gredos.

Cambon, Glauco (2014). Eugenio Montale's poetry: A dream in reason's presence. Princeton: Princeton University Press.

CASADO, Miguel (2006). Los artículos de la polémica y otros textos sobre poesía. Madrid: Biblioteca Nueva.

Gale, Lenore (1981). Poesía y comunicación en la lírica contemporánea hispanoamericana. London: University Microfilms internacional.

GARCíA MARTín, José Luis (1988). La generación de los ochenta. Valencia: Consorci d'editores valencians.

GARCÍA MONTERO, Luis (1996). "Una musa vestida con vaqueros". Aguas territoriales. Valencia: Pre-Textos.

JimÉnEZ millán, Antonio (1994). “Antonio Jiménez Millán”. Luis Muñoz (ed.). El lugar de la poesía. Granada: Diputación provincial de Granada.

LANZ, Juan José (2007). La poesía durante la transición y la generación de la democracia. Madrid: Editorial Devenir.

LLANA, Ruth (2014). tiembla. Sevilla: Point de Lunettes.

LLANA, Ruth (2015). estructuras. Valencia: Ejemplar único.

LLANA, Ruth (2017). umbral. Oviedo: Ediciones Malasangre.

LÓPeZ-CARBAllo, Pablo. "Confluencias hispánicas”. Bulletin of Hispanic Studies 94-10 (2017): 1117- 1132.

MÉNDEZ RUBIO, Antonio. "Memoria de la desaparición: notas sobre poesía y poder". Anales de literatura española 17 (2004): 121-144.

Milán, Eduardo. "Nicanor Parra. El riesgo de antescribir". Estudios públicos nº136 (Primavera 2014).

MonTALE, Eugenio (1995). De la poesía. Valencia: Pre-Textos.

MORA, Vicente Luis (2006). Singularidades. Ética y poética de la literatura española actual. Madrid: Bartleby. 
Morabito, Fabio (2006). “Introducción”. Montale, Eugenio. Poesía completa. Barcelona: Galaxia Gutemberg.

MORANTE, José Luis (2016). “Entrevista”. Uno y cero ediciones.

SALGAdO, María (2012). ready. Madrid: Arrebato libros.

SAlgado, María (2016). Hacía un ruido. Frases para un film político. Valencia: Ediciones Contrabando.

SCHOpf, Federico (2000). Del Vanguardismo a la antipoesía. Ensayos sobre la poesía en chile. Santiago de Chile: Lom Ediciones.

Su XiaOXiaO (2015). La casa de la ciénaga, Madrid: Ártese quien pueda.

VillenA, Luis Antonio de (1986). Postnovísimos. Madrid: Visor.

ViLLENA, Luis Antonio de (2010). La inteligencia y el hacha. Madrid: Visor.

VV. AA. Alicia Bajo Cero (1996). Poesía y poder. Valencia: Ediciones Bajo Cero.

VV. AA. (2011) Poetas ante la incertidumbre. Madrid: Visor. 